\title{
Introduction: Re-intervention for bioprosthetic valve failure: Is less more, or just less?
}

Richard Lee, MD, JD, MBA

Drs Malaisrie and Greason provide expert insight into management of bioprosthetic aortic valve failure through different lenses. They both examine the same data and acknowledge similar pros and cons of open replacement versus transcatheter valve-in-valve insertion. The core difference is how they weigh the value of the trade off between short-term morbidity and mortality versus longterm benefit. Dr Malaisrie supports valve-in-valve insertion, whereas Dr Greason supports reoperation. This is an age-old dilemma that is particularly relevant in cardiac surgery. We have seen it in coronary artery disease and atrial fibrillation. We are now seeing it with aortic valve disease. The reality is the answer will change over time and conditions, including the view of the surgeon. What we all agree with is that it will always depend on the patient and her preference. Sometimes, a lessinvasive approach is more beneficial to the patient; other times, it is worse than a more-invasive approach. It is up to the reader to carefully review both views and decide what his or her own approach should be today and reevaluate it as more data emerge. The only certainty is that it will always change.
From the Division of Cardiothoracic Surgery, Department of Surgery, Medical College of Georgia, Augusta University, Augusta, Ga.

Disclosures: The author reported no conflicts of interest.

The Journal policy requires editors and reviewers to disclose conflicts of interest and to decline handling or reviewing manuscripts for which they may have a conflict of interest. The editors and reviewers of this article have no conflicts of interest.

Received for publication Jan 29, 2021; revisions received Jan 29, 2021; accepted for publication Jan 29, 2021; available ahead of print Feb 17, 2021.

Address for reprints: Richard Lee, MD, JD, MBA, Division of Cardiothoracic Surgery, Department of Surgery, Medical College of Georgia, 1120 15th St, BA4300, Augusta, GA 30912 (E-mail: RICKLEE@ augusta.edu).

J Thorac Cardiovasc Surg 2022;163:939

0022-5223/\$36.00

Copyright (C) 2021 Published by Elsevier Inc. on behalf of The American Association for Thoracic Surgery

https://doi.org/10.1016/j.jtcvs.2021.01.119

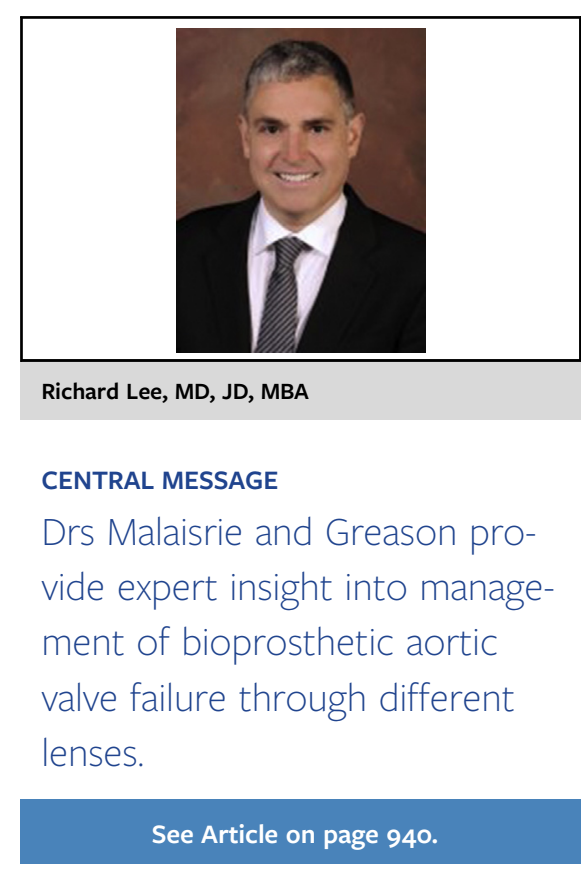

CENTRAL MESSAGE

vide expert insight into manage-

ment of bioprosthetic aortic

valve failure through different

See Article on page 940. 